\title{
Pendekatan Motivasi Intrinsik dan Ekstrinsik dalam Mengukur Penggunaan Layanan Mobile Payment (Studi Kasus Pada Pengguna LinkAja di Kota Denpasar)
}

\author{
Gusi Putu Lestara Permana ${ }^{1}$, Victor Hiu², I Gusti Ngurah Darma Paramartha ${ }^{3}$ \\ 1,2,3 Universitas Pendidikan Nasional Denpasar \\ e-mail: ${ }^{1}$ lestarapermana@ undiknas.ac.id, ${ }^{2}$ hiu.victor03@yahoo.com, ${ }^{3}$ ngurahdarma@undiknas.ac.id
}

\begin{tabular}{ccc}
\hline Diterima & Direvisi & Disetujui \\
$19-01-2021$ & $18-03-2021$ & $25-03-2021$ \\
\hline
\end{tabular}

\begin{abstract}
Abstrak - Maksud dari penelitian ini untuk menukur minat penggunaan layanan m-payment LinkAja di Denpasar dan diukur dengan mengadopsi teori Model Penerimaan Teknologi atau TAM yang dimodifikasi dan disesuaikan dengan menambahkan motivasi ekstrinsik yaitu perceived enjoyment. Penelitian ini mengambil populasi seluruh pengguna mobile payment LinkAJa yang ada di kota Denpasar yang kemudian dari seluruh populasi itu diperkecil lagi dengan menggunakan cara Insidental sampling dan didapatkan sampel penelitian sebanyak 95 sampel yang datanya dikumpulkan dengan menggunakan kuesioner, selanjutnya data yang sudah diperoleh dianalisis dengan partial least square melalui SmartPLS 3. Setelah dianalis riset ini memanifestasikan bahwa penambahan konstruk instrinsik dan ekstrinsik mampu memprediksi minat penggunaan aplikasi mobile payment LinkAja di Kota Denpasar.
\end{abstract}

Kata Kunci:Model Penerimaan Teknologi (TAM), Motivasi Intrinsik, Motivasi Ektrinsik, Perceived Enjoyment, Mobile Payment, LinkAJa.

Abstract - The purpose of this study was to measure the interest in using LinkAja m-payment services in Denpasar and measured by adopting a modified and adapted technology acceptance model or TAM theory by adding extrinsic motivation, namely perceived enjoyment. This study took a population of all LinkAJa mobile payment users in the city of Denpasar, which then reduced the entire population using incidental sampling and obtained a research sample of 95 samples whose data were collected using a questionnaire, then the data that had been obtained were analyzed by partial least. square through SmartPLS 3. After analyzing this research, it manifests that the addition of intrinsic and extrinsic constructs is able to predict the interest in using the LinkAja mobile payment application in Denpasar City.

Keywords: Technology Acceptance Model (TAM), Intrinsic Motivation, Extrinsic Motivation, Perceived Enjoyment, Mobile Payment, LinkAJa.

\section{PENDAHULUAN}

Salah satu kategori financial technology yang sekarang sedang populer di Indonesia adalah mobile payment atau m-payment (Emi Amelia, 2019). Yang mana konsumen telah mengkonversikan uangnya kedalam bentuk digital, mekanismenya konsumen hanya cukup menggunakan metode transfer uang atau dengan menggunakan scan $Q R$ code pada semua merchant yang berkolaborasi dengan provider mobile payment yang telah diajak bekerjasama. Mobile payment adalah salah satu pendekatan yang terbaru dibidang keuangan yang mana uang ditransfer kepada pengguna lainnya yang berjalan di platform internet dan gawai (Amoroso \& Magnier-Watanabe, 2012). Dalam penelitian Song Lee Yeng (Leng et al., 2018) berpendapat jika layanan mobile payment dapat memberikan dampak yang positif terhadap perekonomian dan dapat memberikan kenyamanan terhadap konsumen.

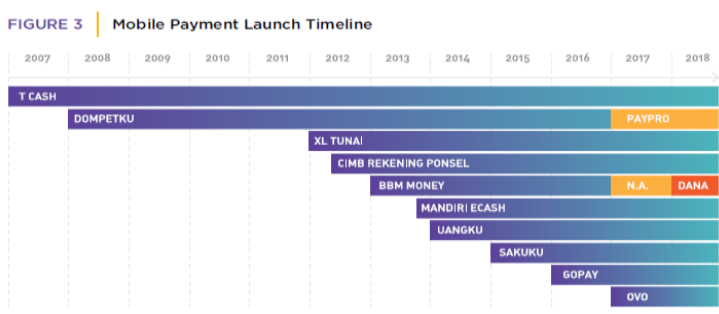

Sumber: Metra Digital Innovation (2018)

Gambar 1. Awal Penggunaan Mobile Payment Di Indonesia

Berdasarkan data yang diterbitkan oleh Metra Digital Innovation pada tahun 2018, terlihat pada Gambar 1 inisiasi pembayaran digital secara mobile di tahun 2007 dan yang menjadi pelopor utama mobile payment ini adalah PT. Telekomunikasi Indonesia yang menciptakan Telkomsel Cash (TCash), yang kemudian dikenalkan kepada khalayak ramai padabulan januari 2007. (Fintech Singapore, 2018) 
Mobile payment T-Cash sendiri menawarkan banyak kemudahan kepada penggunanya mulai dari kemudahan dalam isi saldo, kemudahan dalam bertransaksi, dan tentunya lebih aman karena pengguna tidak membawa lagi uang yang uang fisik tetapi pengguna hanya cukup menggunakan perpindahan uang secara transfer atau scan kode QR.

Dibalik semua kemudahan yang diberikan oleh T-cash terhadap penggunanya belum tentu bisa menjamin bahwa mobile payment $\mathrm{T}$-cash ini bisa menjadi mobile payment yang paling diminati serta digunakan oleh masyarakat. Perusahaan-perusahaan dalam bidang perbankan ataupun non perbankan saling bersaing dan berlomba-lomba dalam menciptakan aplikasi mobile payment.

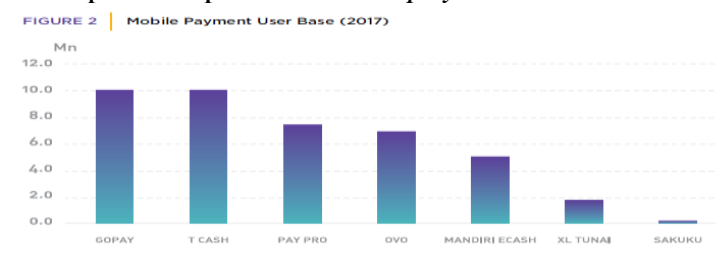

Sumber: mobile payment (2017)

Gambar 2. Data Pengguna T-Cash Tahun 2017

Berdasarkan ilustrasi diatas, terlihat persaingan yang ketat dalam industri mobile payment pada tahun 2017, pada tahun ini industri mobile payment didominasi oleh aplikasi Go-pay yang merupakan aplikasi mobile payment besutan Go-jek yang memiliki jumlah yang pengguna yang sama. Dengan kata lain T-cash mampu ditandingi oleh Gopay.

Tabel 1. Peringkat Penggunaan Aplikasi $M$ Payment

\begin{tabular}{|c|c|c|}
\hline No & Aplikasi M-Payment & $\begin{array}{c}\text { Persentase } \\
\text { Penggunaan }\end{array}$ \\
\hline 1. & GO-PAY & $79,39 \%$ \\
\hline 2 & OVO & $58,42 \%$ \\
\hline 3 & T-Cash & $55,52 \%$ \\
\hline 4 & DANA & $34,18 \%$ \\
\hline 5 & PayTren & $19,27 \%$ \\
\hline 6 & $\begin{array}{c}\text { Aplikasi M-payment } \\
\text { lainnya }\end{array}$ & $0,97 \%$ \\
\hline 7 & $\begin{array}{c}\text { Tidak menggunakan } \\
\text { aplikasi m-payment }\end{array}$ & $3,70 \%$ \\
\hline
\end{tabular}

Sumber : DailySocial Fintech Report 2018

Berdasarkan publikasi yang dilakukan DailySocial Fintech pada tahun 2018 mengenai survei perkembangan penggunaan mobile payment di Indonesia. Dimana hasil dari survei tersebut menunjukkan bahwa mobile payment yang terpopuler di Indonesia tahun 2018 adalah Go-Pay, dengan persentase usernya lebih unggul dibandingkan dengan mobile payment lainnya. Terlihat juga bahwa T-Cash menempati posisi ketiga serta jumlah penggunanya dapat di saingi oleh Go-pay dan OVO yang merupakan aplikasi mobile payment pendatang baru. Dengan demikian jumlah pengguna T-cash mengalami penurunan.

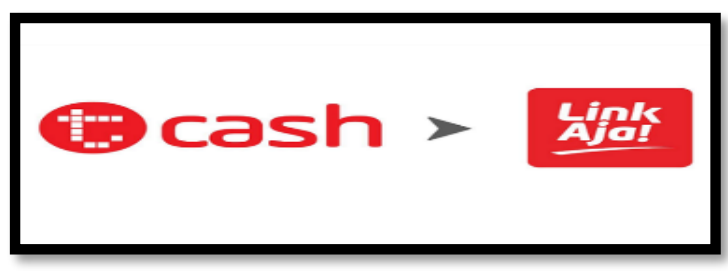

Sumber : LinkAja

Gambar 3. T-Cash berubah Menjadi LinkAja

Berkenaan dengan terjadinan penurunan pengguna, T-Cash memutar strateginya dengan merubah namanya layanannya menjadi LinkAja pada 22 Februari 2019. LinkAja sendiri adalah mobile payment hasil gabungan antara T-Cash dan layanan uang elektronik dari macam-macam BUMN, yaitu Bank BNI, BRI dan Mandiri. Tujuan gabungan tersebut tidak lain untuk mempermudah pelayanan transaksi secara online. Perubahan T-Cash menjadi LinkAja tidak memberikan perbedaan yang signifikan. Dalam melakukan registrasi untuk menggunakan LinkAja, user T-Cash tidak perlu melakukan registrasi lagi melainkan hanya tinggal melakukan pembaharuan pada aplikasi T-Cash di supermarket aplikasi. Selain itu fitur dan layanan yang dahulu terdapat di T-Cash juga masih bisa diakses pada LinkAja.

Tabel 2. Pergerakan penggunaan M-Payment Tahun 2019

\begin{tabular}{|l|l|l|l|}
\hline $\begin{array}{l}\text { Produk } \\
\text { M-Payment }\end{array}$ & $\begin{array}{l}\text { Kesadaran } \\
\text { merek }\end{array}$ & $\begin{array}{l}\text { Top } \\
\text { Of } \\
\text { Mind. }\end{array}$ & $\begin{array}{l}\text { Niat } \\
\text { Menggunakan } \\
\text { di Mepan. } \\
\text { Depan }\end{array}$ \\
\hline GOPAY & 100 & 65,6 & 67,4 \\
\hline OVO & 96,2 & 30,9 & 33,8 \\
\hline DANA & 50,3 & 1,8 & 6,8 \\
\hline PAYTREN & 47,1 & 1,2 & 1,2 \\
\hline LINKAJA & 35,0 & 0,3 & 0,3 \\
\hline
\end{tabular}

Sumber : Alvara Research Center

Berdasarkan survei yang dilakukan oleh Alvara Research Center tanggal 3-10 april 2019 yang terkait dengan layanan digital payment. Dimana responden yang berpartisipasi dalam survei tersebut sebanyak 1.204 orang yang berasal dari Bali, Yogyakarta, Jabodetabek, dan Manado. Hasil dari survei tersebut terlihat bahwa LinjAja sendiri masih berada di posisi kelima dan dapat disaingi oleh aplikasi mobile payment lainnya. Artinya secara pengguna LinkAja masih belum mampu merangkul pangsa pasarnya. (Otoritas Jasa Keuangan, 2018)

Berdasarkan terjadinya penurunan minat menggunakan mobile payment $\mathrm{T}$-Cash yang telah di jelaskan, hilangnya pangsa pasar LinkAja, serta perubahan nama dari t-cash menjadi LinkAja menyebabkan konsumen kurang aware terhadap produk ini. Hal tersebut membuat peneliti ingin mengatahui aspek apa saja yang mempengaruhi minat penggunaan mobile payment LinkAja. Motivasi intrinsik dan motivasi ekstrinsik merupakan dua factor yang mendorong minat penggunaan suatu sistem informasi (Permana, 2017). 
Motivational Model dikembangkan oleh Davis et al. tahun 1992 menggabungkan model penerimaan teknologi dengan kedua konstruk utama dari motivasi yang memberikan pengaruh terhadap para pengguna dalam penerimaan system teknologi .(Kim et al., 2007) menyatakan persepsi kegunaan merupakan bagian dari motivasi ektrinsik, oleh karena itu motivasi ektrinsik diartikan sebagai konstruk yang mengandung rancangan persepsi kegunaan pada model penerimaan teknologi (TAM). Pada perumusan Motivational Model, Davis menyertakan kontruk persepsi kesukaan (perceived enjoyment) sebagai motivasi intrinsik. Persepsi kesukaan ini merupakan tingkat kepuasan pengguna dalam memakai sebuah system informasi. Penambahan konstruk ini menjadikan model penerimaan teknologi (TAM) sebagai model teoritis yang melihat persepsipengguna dari dua arah.(Fagan et al., 2008)

\section{Pokok Permasalahan}

Berdasarkan fenomena dimana T-Cash yang menjadi pencetus pertama aplikasi pembayaran digital di indonesia yang mampu disaingi Gopay dan OVO yang merupakan m-payment pendatang baru dan kurangnya kepopuleran LinkAja dibandingkan dengan aplikasi mobile payment lainnya, serta strategi perubahan nama yang dilakukan (Setiawan et al., 2019), maka peneliti ingin menguji bagaimana minat perilaku penggunaan layanan mobile payment linkaja yang diukur dengan menggunakan teori model TAM yang dimodifikasi dengan menambahkan konstruk perceived enjoyment dan teori motivasional model (Leng et al., 2018).

\section{Mobile Payment}

Mobile payment merupakan sistem pembayaran bagi jasa maupun barang yang menggunakan sebuah perangkat seperti mobile phone seluler dan Personal Digital Asisstant (PDA) . Mobile payment merupakan suatu metode dalam pembayaran yang menggunakan sebuah perangkat mobile seperti mobile phone dan personal digital assistant untuk menjalankan dan mengkonfirmasi pembayaran barang atau jasa serta dapat dilakukan dimanapun (Pertawijaya, 2015).

\section{Model Penerimaan Teknologi (TAM)}

Sebuah Model yang dikembangkan oleh Davis pada tahun 1989 yang dimana lingkup pembahasannya merupakan perilaku psikologis individu kepada suatu objek. Model ini memiliki dua konstruk utama yaitu persepi kegunaan (perceived usefulness) dan persepsi kemudahan penggunaan. (Ma \& Liu, 2004)

\section{Motivasional Model}

Motivasional Model (MM) merupakan yang pertama kali dikemukakan oleh Davis et al., (1992). Motivasional model menyatakan terdapat dua konstruk dari motivasi yang tidak lain adalah motivasi intrinsik dan motivasi ekstrinsik. MM mengacu pada teori psikologi untuk menjelaskan teori motivasi sebagai penjelas perilaku dalam konteks adopsi dan penggunaan sistem informasi. Davis et al., (1992) mengartikan motivasi ekstrinsik sebagai kinerja sebuah aktivitas karena dianggap mempunyai peran yang penting untuk mencapai hasil yang bernilai tambah dari aktivitas tersebut, Davis menjadikan perspektif motivasi dan memasukkan persepsi enjoyment serta mendeskripsikan penerimaan informasi teknologi dari perspektif motivasi ektrinsik dan intrinsik.

\section{Kerangka Penelitian}

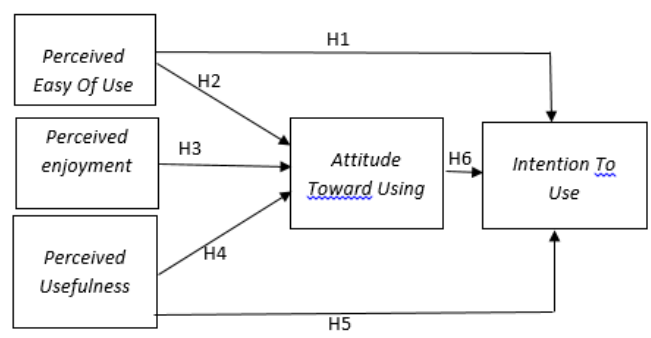

Gambar 4. Kerangka Penelitian

Berdasarkan kerangka penelitian, terdapat 6 hipotesis yang dikembangkan.

H1: Diduga Perceived Ease of Use berpengaruh positif terhadap Intention To Use

H2: Diduga Perceived easy of use berpebgaruh positif terhadap attitude toward using.

H3: Diduga Perceived enjoyment berpengaruh positif terhadap attitude toward using .

H4: Diduga Perceived usefulness berpengaruh positif terhadap attitude toward using.

H5: Diduga Perceived usefulness berpengaruh positif terhadap intention to use.

H6: Diduga Attitude toward using berpengaruh positif terhadap intention to use.

\section{METODE PENELITIAN}

\section{Lokasi, Populasi dan Sampel}

Riset ini dilangsungkan di kota Denpasar, pemilihan lokasi didasarkan pada kota dengan pengguna internet terbanyak di Provinsi Bali (APJI Indonesia, 2017)

Observasi ini menggunakan seluruh pemakai layanan mobile payment LinkAja sebagai populasi yang mana secara jumlah tidak dapat diketahui secara pasti jumlahnya.

Untuk memudahkan mencari data maka digunakan teknik sampling untuk menyederhanakan jumlah dan merepresentasikan populasi, yang kemudian digunakanlah teknik Insidental sampling sebagai teknik sampling yang mana menurut (Sugiono, 2009) sampel ditentukan secara kebetulan dan apabila dilihat orang tersebut sesuai untuk dijadikan sumber data

\section{Teknik Pengumpulan Data}

Data dikumpulkan dengan kuesioner yang 
disebar secara merata dikota Denpasar sebanyak 95 buah kuesioner. Responden tanpa paksaan menjawab pernyataan yang sudah diturunkan dari indikator lalu dilanjutkan dengan dianalisis dengan Structural Equation Model (SEM) karena penelitian ini menguji sebuah model yang dimodifikasi dan dijalankan dengan perangkat lunak Partial Least Square (PLS).

\section{HASIL DAN PEMBAHASAN}

\section{Uji Validitas}

Validitas Konvergen

Tabel 3. Outer Loading

\begin{tabular}{|c|c|c|c|}
\hline Variabel & $\begin{array}{c}\text { Outer } \\
\text { Loading }\end{array}$ & AVE & Keterangan \\
\hline $\begin{array}{c}\text { Perceived } \\
\text { Easy Of Use }\end{array}$ & & 0.806 & Valid \\
\hline PEOU 1 & 0.803 & & Valid \\
\hline PEOU 2 & 0.862 & & Valid \\
\hline PEOU 3 & 0.830 & & Valid \\
\hline PEOU 4 & 0.821 & & Valid \\
\hline PEOU 5 & 0.717 & & Valid \\
\hline PEOU 6 & 0.796 & & Valid \\
\hline $\begin{array}{l}\text { Perceived } \\
\text { Enjoyment }\end{array}$ & & 0.923 & Valid \\
\hline PE 1 & 0.924 & & Valid \\
\hline PE 2 & 0.921 & & Valid \\
\hline $\begin{array}{l}\text { Perceived } \\
\text { Usefulness }\end{array}$ & & 0.802 & Valid \\
\hline PU 1 & 0.758 & & Valid \\
\hline PU 2 & 0.843 & & Valid \\
\hline PU 3 & 0.825 & & Valid \\
\hline PU 4 & 0.814 & & Valid \\
\hline PU 5 & 0.764 & & Valid \\
\hline $\begin{array}{c}\text { Attitude } \\
\text { Toward } \\
\text { Using }\end{array}$ & & 0.879 & Valid \\
\hline ATU 1 & 0.919 & & Valid \\
\hline ATU 2 & 0.799 & & Valid \\
\hline ATU 3 & 0.914 & & Valid \\
\hline $\begin{array}{c}\text { Intention To } \\
\text { Using }\end{array}$ & & 0.862 & Valid \\
\hline IT 1 & 0.874 & & Valid \\
\hline IT 2 & 0.849 & & Valid \\
\hline IT 3 & 0.862 & & Valid \\
\hline
\end{tabular}

Sumber: Data Diolah (2020)

Bagan diatas menyatakan angka validitas konvergen diatas 0.7 , kemudian nilai factor loading adalah korelasi antar indikator dan konstruk yang mana pada tabel 3 terlihat bahwa konstruk memiliki korelasi yang tinggi sehingga menerangkan validitas semakin baik. Untuk nilai AVE membuktikan bahwa hasil dari pengujian ini memenuhi aturan uji validitas pada PLS yang ditunjukkan dengan nilai AVE diatas 0.5.(Willy Abdillah, 2015)

\section{Uji Validitas Diskriminan}

Tabel 4. Korelasi Variabel Laten

\begin{tabular}{|c|c|c|c|c|c|c|c|}
\hline & \multirow{2}{*}{ AVE } & Akar & \multicolumn{6}{|c|}{ Korelasi } \\
\cline { 4 - 8 } & & AVE & ATU & IT & PE & PEOU & PU \\
\hline ATU & 0.772 & 0.879 & 0.879 & & & & \\
\hline IT & 0.743 & 0.862 & 0.772 & 0.862 & & & \\
\hline PE & 0.851 & 0.923 & 0.81 & 0.686 & 0.923 & & \\
\hline PEOU & 0.65 & 0.806 & 0.69 & 0.635 & 0.733 & 0.806 & \\
\hline PU & 0.643 & 0.802 & 0.767 & 0.698 & 0.805 & 0.602 & 0.802 \\
\hline
\end{tabular}

Sumber: Data Diolah (2020)

Bagan diatas menjabarkan akar kuadrat AVE memiliki nilai variabel lebih beasr dari korelasi variabel laten dengan variabel lainnya. Komparasi akar AVE dengan variabel laten menunjukkan Indikator pada penelitian memenuhi kaidah parameter uji validitas diskriminan.

\section{Uji Reliabilitas}

\section{Tabel 4. Reliabilitas}

\begin{tabular}{|c|c|c|c|}
\hline Variabel & $\begin{array}{c}\text { Composite } \\
\text { Reliability }\end{array}$ & $\begin{array}{c}\text { Cronbachs } \\
\text { Alpha }\end{array}$ & Keterangan \\
\hline Perceived Easy Of Use & 0.917 & 0.891 & Reliabel \\
\hline Perceived Enjoyment & 0.920 & 0.825 & Reliabel \\
\hline Perceived Usefulness & 0.900 & 0.861 & Reliabel \\
\hline Attitude Toward Using & 0.910 & 0.852 & Reliabel \\
\hline Intention To Use & 0.896 & 0.827 & Reliabel \\
\hline
\end{tabular}

Sumber: Data Diolah (2020)

Ouput dari yang ditunjukkan pada pada tabel 4, nilainya lebih dari 0.70 Bisa disimpulkan bahwa seluruh variabel reliable.

\section{Pengujian Hipotesis}

Rule of thumbs untuk pengujian hipotesis menggunakan $\mathrm{T}$ hitung, harus diatas 1,64 karena menggunakan hipotesis dengan arah hipotesis telah ditentukan dengan alpha sebesar 5\%.

Tabel 6. Path Coefficients

\begin{tabular}{|c|c|c|c|c|}
\hline & $\begin{array}{c}\text { Original } \\
\text { Sample } \\
(\mathrm{O})\end{array}$ & $\begin{array}{c}\text { Sample } \\
\text { Mean (M) }\end{array}$ & $\begin{array}{c}\text { Standard } \\
\text { Deviation } \\
(\text { STDEV) }\end{array}$ & $\begin{array}{c}\text { T Statistics } \\
(/ \mathrm{O} / \text { STDEV } / \text { ) }\end{array}$ \\
\hline PEOU $\rightarrow$ IT & 0.165 & 0.150 & 0.075 & 2.188 \\
\hline PEOU $\rightarrow$ ATU & 0.201 & 0.209 & 0.083 & 2.416 \\
\hline PE $\rightarrow$ ATU & 0.404 & 0.410 & 0.110 & 3.682 \\
\hline PU $>$ ATU & 0.321 & 0.302 & 0.142 & 2.265 \\
\hline PU $\rightarrow$ IT & 0.228 & 0.234 & 0.111 & 2.058 \\
\hline ATU $\rightarrow$ IT & 0.483 & 0.483 & 0.112 & 4.308 \\
\hline
\end{tabular}

Sumber: Data Diolah (2020)

Berdasarkan Tabel 6 diatas, mengungkapkan bahwa pengujian hipotesis 1 diterima. Hal ini dibuktikan dengan besaran nilai t sebesar 2,188 lebih besar dari 1,64 dan arahnya bernilai positif sebesar 0,165 sehingga sesuai dengan hipotesis $1\left(\mathrm{H}_{1}\right)$ yang dibangun.

Berdasarkan Tabel 6 diatas, mengungkapkan bahwa pengujian hipotesis 2 diterima. Hal ini dibuktikan dengan besaran nilai t sebesar 2,416 lebih besar dari 1,64 dan arahnya bernilai positif sebesar 0,201sehingga sesuai dengan hipotesis $2\left(\mathrm{H}_{2}\right)$ yang dibangun.

Berdasarkan Tabel 6 diatas, mengungkapkan bahwa pengujian hipotesis 3 diterima. Hal ini dibuktikan dengan besaran nilai t sebesar 3,682 lebih besar dari 1,64 dan arahnya bernilai positif sebesar 0,404 sehingga sesuai dengan hipotesis $3\left(\mathrm{H}_{3}\right)$ yang 
dibangun.

Berdasarkan Tabel 6 diatas, mengungkapkan bahwa pengujian hipotesis 4 diterima. Hal ini dibuktikan dengan besaran $\mathrm{t}$ sebesar 2,265 lebih besar dari 1,64 dan arahnya bernilai positif sebesar 0,321 sehingga sesuai dengan hipotesis $4\left(\mathrm{H}_{4}\right)$ yang dibangun.

Berdasarkan Tabel 6 diatas, mengungkapkan bahwa pengujian hipotesis 5 diterima. Hal ini dibuktikan dengan besaran nilait sebesar 2,058 lebih besar dari 1,64 dan arahnya bernilai positif sebesar 0,228 sehingga sesuai dengan hipotesis $5\left(\mathrm{H}_{5}\right)$ yang dibangun.

Berdasarkan Tabel 6 diatas, mengungkapkan bahwa pengujian hipotesis 6 . Hal ini dibuktikan dengan besaran nilai t sebesar 4,308 lebih besar dari 1,64 dan arahnya bernilai positif sebesar 0,483 sehingga sesuai dengan hipotesis $6\left(\mathrm{H}_{6}\right)$ yang dibangun.

\section{KESIMPULAN}

Simpulan penelitian ini menyatakan bahwa penambahan konstruk instrinsik dan ekstrinsik mampu memprediksi minat penggunaan aplikasi mobile payment LinkAja, hal ini terbukti dari tes terhadap hipotesis yang telah dilakukan yang menunjukkan bahwa seluruh hipotesis yang telah dirumuskan diterima.

Untuk mengurangi keterbatasan dan kekurangan dalam penelitian ini terdapat saran yang bias dilakukan:

1. Sampel untuk penelitian selanjutnya dipilih dengan lebih spesifik,

2. Lokasi penelitian diperluas untuk memperoleh gambaran secara merata mengenai penggunaan m-payment.

3. Menambahkan konstuk baru yang berkaitan dengan motivasi eksternal guna memperbaharui model yang sudah ada.

\section{REFERENSI}

Amoroso, D. L., \& Magnier-Watanabe, R. (2012). Building a research model for mobile wallet consumer adoption: The case of mobile Suica in Japan. Journal of Theoretical and Applied Electronic Commerce Research, 7(1), 94-110. https://doi.org/10.4067/S071818762012000100008

APJI Indonesia. (2017). Penetrasi \& Profil Perilaku Pengguna Internet Indonesia. Apjii, 51. https://apjii.or.id/survei2018s/download/TK5o JYBSyd8iqHA2eCh4FsGELm3ubj

Emi Amelia. (2019). ANALISIS PERILAKU MINAT MENGGUNAKAN MOBILE PAYMENT DENGAN PENDEKATAN TECHNOLOGY ACCEPTANCE MODEL 3
(Studi pada Pengguna Aplikasi Pembayaran OVO). In UNIVERSITAS PENDIDIKAN INDONESIA.

Fagan, M. H., Neill, S., \& Wooldridge, B. R. (2008). Exploring the intention to use computers: An empirical investigation of the role of intrinsic motivation, extrinsic motivation, and perceived ease of use. Journal of Computer Information Systems, 48(3), 31-37. https://doi.org/10.1080/08874417.2008.11646 019

Fintech Singapore. (2018). Indonesia Fintech Landscape Report May 2018. May. www.fintechnews.sgwww.facebook.com/Finte chIndonesia/

Kim, S., Na, E. K., \& Ryu, M. H. (2007). Factors affecting user participation in video UCC (usercreated contents) services. Proceedings of the 3rd Communities and Technologies Conference, $C$ and $T$ 2007, 209-224. https://doi.org/10.1007/978-1-84628-905-7_11

Leng, S. Y., Talib, A., \& Gunardi, A. (2018). Financial Technologies: A Note on Mobile Payment. Jurnal Keuangan Dan Perbankan, 22(1), 51-62. https://doi.org/10.26905/jkdp.v22i1.1993

Ma, Q., \& Liu, L. (2004). The Technology Acceptance Model. Advanced Topics in End User Computing, Volume 4, October 2017. https://doi.org/10.4018/9781591404743.ch006 .ch000

Otoritas Jasa Keuangan. (2018). OR (Issue 44092). https://dailysocial.id/research/fintech-report2018\#

Permana, G. P. L. (2017). Analisis Faktor-Faktor Penerimaan Internet Banking Dengan Menggunakan Pendekatan Technology Acceptance Model ( TAM ) Dengan Penambahan Peran Motivasi Extrinsic dan Intrinsic. Jurnal Ilmiah Akuntansi Dan Bisnis, 2(1), 33-41.

Setiawan, T., SINAGA, E., Pemilihan, D., Mahasiswa, E. U., Chan, A., Maharani, M., \& Tresna, P. W. (2019). Persepsi Kredibilitas, Sikap, Dan Norma Subjektif Terhadap Minat Menggunakan Layanan Mobile Payment Linkaja Di Kota Semarang. Program Sarjana Fakultas Ekonomi, 1(2), 259-265. http://eprints.undip.ac.id/76417/

Sugiono. (2009). Metode Penelitian Kuantitatif, Kualitatif dan $R \& D$ (p. 96).

Willy Abdillah, J. H. (2015). Partial Least Square (PLS): alternatif structural equation modeling (SEM) dalam penelitian bisnis. 